\title{
Geology of the FBI lab and the challenge to the admissibility of forensic geology in US court
}

${ }^{1}$ FBI Laboratory, Quantico, VA 22556, USA; *Corresponding author, E-mail: Jodi.Webb@ic.fbi.gov

(Received: November 2, 2016; Revised accepted: March 5, 2017)

http://dx.doi.org/10.18814/epiiugs/2017/v40i2/017013

Soil and geologic evidence has been examined in the FBI Laboratory since 1939, and long admitted into trials, both in the US and abroad. However, to the best our knowledge soil evidence did not undergo a formal admissibility challenge within the US court systems until $29^{\text {th }}$ January 2016. Forensic soil analysis is typically a comparison between two or more samples to see whether they originated from different sources. When soil samples are indistinguishable, the possibility that they originated from a single source cannot be eliminated. The challenge in State of Kansas v. Kyle Flack, 13CR104 (2016), involved the admissibility of soil comparisons at the trial, as well as the qualifications of the forensic geologist who conducted the examinations. The views expressed are those of the authors and do not necessarily reflect the official policy or position of the FBI. Names of commercial manufacturers are provided for identification purposes only, and inclusion does not imply endorsement of the manufacturer or its products or services by the FBI.

\section{Introduction}

Expert testimony in US courts may be subjected to an admissibility hearing before being accepted in a particular proceeding. In 1923, the D.C. Court of Appeals ruled in Frye v United States (Frye, 1993) that a scientific analysis must be sufficiently established to have gained "general acceptance" in its field before it can be admitted into testimony. Over 50 years later, the United States adopted Rule 702 of the Federal Rules of Evidence, which broadened the "general acceptance" test and laid out the criteria that a judge may use to assess the admissibility of a scientific analysis. The Supreme Court affirmed in 1993 (Daubert v Merrell Pharmaceuticals, 1993) that Rule 702 superseded the "general acceptance" standard of Frye and that the judge, acting as a gatekeeper, may consider whether a particular scientific discipline meets the standards set by their jurisdiction and whether or not it can be considered "rigorous and reliable." Most States (including Kansas) now use the guidelines laid out in Daubert with only a handful of states relying on Frye or Frye-hybrid admissibility criteria.

\section{The Case}

As part of a quadruple homicide investigation, the FBI Laboratory received multiple soil samples from the wheel wells of a vehicle of interest to compare with one soil exemplar from a roadside location near where the body of one of the victims was discovered.

The soil samples were examined under a stereobinocular reflectedlight microscope to assess soil components for overall size and shape of aggregated particles, suitability for comparison, and to determine whether the samples showed evidence of contributions from multiple sources. The color was determined by comparison to a Munsell soil color chart in a light box using simulated daylight. Grain mounts of the mineral components were examined using a petrographic microscope to characterize the minerals present, their approximate proportions, their size and shape range, and the textural appearance of the grains.

The soils recovered from the passenger-side rear wheel well of the vehicle were indistinguishable in color, texture, and composition from the soil submitted from the crime scene. Therefore, the crime scene could not be eliminated as a possible source of the soil on the rear passenger-side wheel well. The supporting documentation to the forensic report included portions of a geologic map published by the Kansas Geological Survey and a Soil Survey map published by US Department of Agriculture (SSURGO), both of the area around the crime scene. These maps illustrated that while the soil from the vehicle was similar to the soil submitted from the crime scene, soils mapped as being similar to the crime scene extend along the unpaved road in question.

Soils recovered from the other three wheel wells of the vehicle were different than the soil sample recovered from the crime scene, therefore eliminating the crime scene as the source of those samples. No additional soil exemplars were submitted for this case so a possible source(s) of these soils was not determined.

\section{The Hearing}

Because soil evidence had not been routinely presented in the Kansas state courts, the defense attorney in Flack challenged the admissibility of the soil comparisons. In response, a closed-session admissibility 
hearing was held in which a forensic geologist from the FBI Laboratory was questioned by attorneys for both the prosecution and defense. The forensic geologist was questioned on a range of topics including: 1) the witness's education and training, experience performing and testifying in forensic soil examination cases, and history of participation in proficiency testing, 2) the accreditation and quality system of the FBI Laboratory, 3) the methods used and if these methods were in common use outside of a forensic context, 4) the results of the examination in this specific case, 5) the interpretation of these results, and 6) the forensic report technical review process. The defense challenged the conclusion reached by the forensic geologist and sought to bar presentation of the soil evidence at trial. The judge, however, ruled that the soil evidence, as examined and reported, was admissible in the subsequent criminal trial, and placed no limits on the geologist's testimony.

As has been shown in numerous publications, (Murray, 2004; Pye, 2007) forensic geology examinations can help find hidden bodies, possibly link people and objects together and to a geographic location, and provide investigative leads. Having successfully weathered an admissibility challenge makes it much more likely that forensic geology examinations will be performed in future cases, and be subsequently admitted into court.

\section{References}

Daubert v. Merrell Dow Pharmaceuticals, 1993, 509 U.S. 579, 596, USA. Frye v. United States 292 Fed. 1013 (D.C. Cir. 1923).

Murray, R.C., 2004, Evidence from the earth: forensic geology and criminal investigation. Mountain Press Publishing, Missoula, $226 \mathrm{p}$.

Pye, K., 2007, Geological and soil evidence: forensic application: CRC Press, Boca Raton, $335 \mathrm{p}$.

Ruffell, A., and McKinley, J., 2008, Geoforensics: John Wiley \& Sons, Hoboken, $332 \mathrm{p}$.

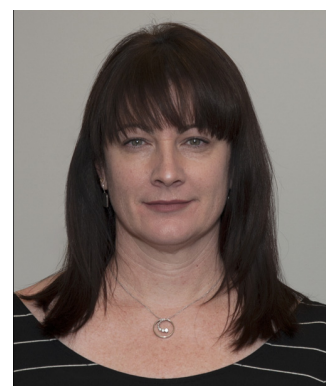

Jodi Webb has a B.S. in Geology from Northern Arizona University and a M.S. in Geology from the University of North Carolina, Chapel Hill. She has worked as a Geologist/Forensic Examiner for the Federal Bureau of Investigation (FBI) Laboratory in Quantico, Virginia, USA since 1997. She conducts examinations of geologic and geologically-derived materials for law enforcement agencies, and provides expert testimony regarding her findings. This include homicides, kidnappings, bombings, product tampering, art crime, fraud and burglary. She also serves as an instructor to law enforcement in the collection and preservation of trace evidence. Jodi is theFBI Adviser for IUGS-IFG. 